\title{
Northern Hemisphere surface freeze-thaw product from Aquarius L-band radiometers
}

\author{
Michael Prince $^{1,2}$, Alexandre Roy ${ }^{3,2,1}$, Ludovic Brucker ${ }^{4,5}$, Alain Royer ${ }^{1,2}$, Youngwook Kim ${ }^{6}$, and \\ Tianjie Zhao ${ }^{7}$ \\ ${ }^{1}$ Centre d'Applications et de Recherches en Télédétection (CARTEL), Université de Sherbrooke, \\ Sherbrooke, QC J1K 2R1, Canada \\ ${ }^{2}$ Centre d'Étude Nordique, Québec, Canada \\ ${ }^{3}$ Département des Sciences de l'Environnement, Université du Québec à Trois-Rivières, \\ Trois-Rivières, QC G9A5H7, Canada \\ ${ }^{4}$ NASA Goddard Space Flight Center, Cryospheric Sciences Laboratory, \\ Code 615, Greenbelt, MD 20771, USA \\ ${ }^{5}$ Universities Space Research Association, Goddard Earth Sciences Technology and Research Studies and \\ investigations, Columbia, MD 21044, USA \\ ${ }^{6}$ Numerical Terradynamic Simulation Group, College of Forestry \& Conservation, \\ the University of Montana, Missoula, MT 59812, USA \\ ${ }^{7}$ State Key Laboratory of Remote Sensing Science, Institute of Remote Sensing and Digital Earth, \\ Chinese Academy of Sciences, Beijing, China \\ Correspondence: Michael Prince (michael.prince@usherbrooke.ca)
}

Received: 22 February 2018 - Discussion started: 20 March 2018

Revised: 6 November 2018 - Accepted: 7 November 2018 - Published: 22 November 2018

\begin{abstract}
In the Northern Hemisphere, seasonal changes in surface freeze-thaw (FT) cycles are an important component of surface energy, hydrological and eco-biogeochemical processes that must be accurately monitored. This paper presents the weekly polar-gridded Aquarius passive L-band surface freeze-thaw product (FT-AP) distributed on the Equal-Area Scalable Earth Grid version 2.0, above the parallel $50^{\circ} \mathrm{N}$, with a spatial resolution of $36 \mathrm{~km} \times 36 \mathrm{~km}$. The FT-AP classification algorithm is based on a seasonal threshold approach using the normalized polarization ratio, references for frozen and thawed conditions and optimized thresholds. To evaluate the uncertainties of the product, we compared it with another satellite FT product also derived from passive microwave observations but at higher frequency: the resampled $37 \mathrm{GHz}$ FT Earth Science Data Record (FTESDR). The assessment was carried out during the overlapping period between 2011 and 2014. Results show that $77.1 \%$ of their common grid cells have an agreement better than $80 \%$. Their differences vary with land cover type (tundra, forest and open land) and freezing and thawing periods. The best agreement is obtained during the thawing transition and over forest areas, with differences between product mean freeze or thaw onsets of under 0.4 weeks. Over tundra, FT-AP tends to detect freeze onset 2-5 weeks earlier than FT-ESDR, likely due to FT sensitivity to the different frequencies used. Analysis with mean surface air temperature time series from six in situ meteorological stations shows that the main discrepancies between FT-AP and FT-ESDR are related to false frozen retrievals in summer for some regions with FT-AP. The Aquarius product is distributed by the U.S. National Snow and Ice Data Center (NSIDC) at https://nsidc.org/data/aq3_ft/versions/5 with the DOI https://doi.org/10.5067/OV4R18NL3BQR.
\end{abstract}




\section{Introduction}

Seasonal freezing and thawing affect over half of the Northern Hemisphere. Landscape freeze-thaw (FT) state transitions show highly variable spatial and temporal patterns, with measurable influences to climate (IPCC, 2014; Peng et al., 2016; Poutou et al., 2004), hydrological (Gouttevin et al., 2012; Gray et al., 1984), ecological (Kumar et al., 2013; Black et al., 2000) and biogeochemical processes (Panneer Selvam et al., 2016; Xu et al., 2013; Schaefer et al., 2011). The surface FT state affects the latent heat exchange and the energy balance at the interface between the soil surface and the overlying medium. The vegetation growing season is sensitive to the annual non-frozen period (Kim et al., 2012), while vegetation net primary production and net ecosystem $\mathrm{CO}_{2}$ exchange with the atmosphere are impacted by FT timing variability (Barr et al., 2009; Kurganova et al., 2007). Comprehensive in situ observational long-term datasets for soil state characteristics across terrestrial environments are still limited or inadequate, mostly for northern remote regions. Remote sensing in the thermal emission domain offers great potential for detecting changes in land surface temperature, but is strongly limited by clouds, vegetation and snow cover (e.g., Langer et al., 2013). Spatially and temporally continuous information on soil freeze-thaw changes is lacking for the regions of both seasonal frozen ground and permafrost.

Passive microwave remote sensing has proven to be sensitive to the surface FT state due to large changes in surface dielectric properties between predominantly frozen and non-frozen conditions, and it offers global coverage. The remotely sensed FT detection capability at the L band $(1.4 \mathrm{GHz})$ has been developed and validated in several studies (Zheng et al., 2017; Roy et al., 2017b; Rautiainen et al., 2012; Schwank et al., 2004). In the L band, the shallow depth contributing to the radiation (around $5 \mathrm{~cm}$ for an unfrozen soil) and the strong permittivity difference between water and ice $\left(\Delta \varepsilon_{\text {ice }}\right.$ water $)$ make it favorable for FT retrieval (Rautiainen et al., 2012, 2014). In recent years, passive Lband FT algorithms were created for NASA's Aquarius (Roy et al., 2015), ESA's soil moisture and ocean salinity (SMOS) (Rautiainen et al., 2016) and NASA's soil moisture active/passive (SMAP) (Derksen et al., 2017) missions. An FT Earth Science Data Record (FT-ESDR) was also produced using a higher microwave frequency at the Ka band $(37 \mathrm{GHz})$ (Kim et al., 2017a). This product offers consistent and continuous global daily information on the FT state for several decades (1979-2016; Kim et al., 2017b). Observations were recorded by the scanning multi-channel microwave radiometer (SMMR), the special sensor microwave/imager (SSM/I) and the SSM/I Sounder (SSMIS).

This study presents the new Aquarius passive FT product for the Northern Hemisphere (Roy et al., 2018), distributed by the US National Snow and Ice Data Center (NSIDC) at http://nsidc.org/data/nsidc-0736/versions/1. The product precision and uncertainties are addressed by comparing Aquarius FT retrievals with the FT-ESDR product for the overlapping period (2011-2014). The Aquarius passive FT product (referred to as FT-AP hereinafter) is based on the Aquarius weekly Level-3 L-band brightness temperature (TB) product (Brucker et al., 2015; NSIDC: http://nsidc. org/data/AQ3_TB/versions/5). The algorithm uses a relative frost factor (FFrel; see, e.g., Rautiainen et al., 2014) based on normalized polarization ratio (NPR) temporal change detection (Roy et al., 2015). To our knowledge, few intercomparisons between L- and Ka-band FT products exist (Derksen et al., 2017), and none evaluated interannual variability differences. However, it is well established that different frequencies interact differently with ground components (vegetation, soil, snow, canopy, etc.). For instance, observations at the $\mathrm{L}$ band are less sensitive than at the Ka band to snow, plant biomass and surface roughness (Ulaby et al., 1986). Being less prone to disturbances above the ground, the Lband emission should give better information on the ground state in forested and snow-covered areas. In addition, since

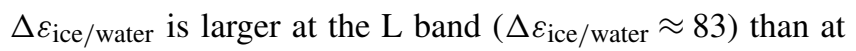
the Ka band $\left(\Delta \varepsilon_{\text {ice/water }} \approx 10\right.$ ) (Artemov and Volkov, 2014), there should be a higher sensitivity to the ground phase transition at the L band. Hence, because differences between products can be attributed to the microwave frequency and the algorithm used, the FT-AP is also compared with surface air temperature (SAT) observations.

The main objective of this study is to present and evaluate the weekly FT-AP by comparing it to the FT-ESDR and to SAT observations across the Northern Hemisphere. First, we describe the new FT-AP product, designed by the algorithm developed by Roy et al. (2015), but applied across the Northern Hemisphere. Then, we investigate the spatial and temporal FT variations from both FT-AP and FT-ESDR products over the Northern Hemisphere. We then investigate the cause of the main differences between products from in situ information. The comparison aims to identify the similarities and differences between L-band and Ka-band FT products for further improvements of FT monitoring across the Northern Hemisphere.

\section{Method}

\subsection{Aquarius passive FT product (FT-AP)}

The Aquarius FT product was generated using the Aquarius weekly averaged polar gridded L-band TB product distributed on the EASE-Grid 2.0, above the parallel $50^{\circ} \mathrm{N}$, with a spatial resolution of $36 \mathrm{~km} \times 36 \mathrm{~km}$ (Brucker et al., 2014). This formatted TB was specially designed for the study of northern regions. For each Aquarius radiometer, the product average TB values were calculated from every measurement made during a week, combining ascending and descending orbits. The FT classification algorithm is based on a seasonal threshold approach (STA) using a frost factor index (FFrel; 
Table 1. Thresholds ( $\tau$ ) applied in Eq. (3) for the whole circumpolar area, derived from the Roy et al. (2015).

\begin{tabular}{lrrr}
\hline Beam & Tundra & Forest & Open land \\
\hline 1 & 0.41 & 0.46 & 0.31 \\
2 & 0.69 & 0.55 & 0.31 \\
3 & 0.63 & 0.54 & 0.41 \\
\hline
\end{tabular}

Eq. 1), introduced by Rautiainen et al. (2014), where FF $_{\mathrm{NPR}}$ is the frost factor based on the normalized polarization ratio between $\mathrm{TB}$ at vertical and horizontal polarizations $\left(\mathrm{TB}_{\mathrm{V}}\right.$ and $\mathrm{TB}_{\mathrm{H}}$; Eq. 2). $\mathrm{FF}_{\mathrm{fr}}$ and $\mathrm{FF}_{\text {th }}$ are reference frozen and thawed frost factors obtained for each pixel and each radiometer by averaging, respectively, the five minimum $\mathrm{FF}_{\mathrm{NPR}}$ found during winter (January and February) and five maximum FF $_{\mathrm{NPR}}$ found during summer (July and August) over the three available dataset periods.

FFrel $=\frac{\mathrm{FF}_{\mathrm{NPR}}-\mathrm{FF}_{\mathrm{fr}}}{\mathrm{FF}_{\mathrm{th}}-\mathrm{FF}_{\mathrm{fr}}}$
$\mathrm{FF}_{\mathrm{NPR}}=\frac{\mathrm{TB}_{\mathrm{V}}-\mathrm{TB}_{\mathrm{H}}}{\mathrm{TB}_{\mathrm{V}}+\mathrm{TB}_{\mathrm{H}}}$

A threshold $(\tau)$ was determined by optimization to classify the surface as frozen or thawed if the FFrel is lower or higher than the threshold (Eq. 3).

$$
\begin{aligned}
& \text { If FFrel }<\tau \rightarrow \text { freeze or } \\
& \text { if FFrel }>\tau \rightarrow \text { thaw. }
\end{aligned}
$$

The thresholds optimized (Table 1) in Roy et al. (2015) over North America for three basic land covers (tundra, forest, open land) were applied over the Northern Hemisphere using the Land Cover Classifications derived from Boston University MODIS/Terra Land Cover Data (LCC $\mathrm{BC}_{\mathrm{BU}}$; see Sect. 2.4). The optimization method calculates the threshold that gives the best accuracy when the product retrievals are compared to in situ air temperature stations. It was shown that optimized thresholds only slightly improved the accuracies by $1 \%$ to $4 \%$ compared to a fixed threshold of 0.5 . For the tundra site, a broad range of threshold values ([0.3-0.7]) caused an insignificant variation of accuracy.

Aquarius operated three non-scanning radiometers at different incidence angles (29.2, 38.4 and 46.3 $)$ and with different $3 \mathrm{~dB}$ footprint sizes (respectively $76 \mathrm{~km} \times 94 \mathrm{~km}$, $84 \mathrm{~km} \times 120 \mathrm{~km}$ and $97 \mathrm{~km} \times 156 \mathrm{~km}$ ). Based on the $\mathrm{LCC}_{\mathrm{BU}}$, the thresholds found in Roy et al. (2015) were used to create FT maps for each radiometer. The three FT maps were then blended to create a fourth map, which offers more complete spatial coverage. For every grid cell, radiometer $2\left(38.4^{\circ}\right)$ was prioritized, then radiometer $1\left(29.2^{\circ}\right)$ was used, while radiometer 3 was only used if data from the other radiometers were not available for the given grid cell. This blended algorithm was chosen based on the performance given for each radiometer in Roy et al. (2015) (radiometer 2 gave the best results, while radiometer 3 gave the worst results). Due to the width of Aquarius' swath and its revisit time, $16.5 \%$ of the terrestrial $36 \mathrm{~km}$ grid cells have less than $95 \%$ observations over the period and $16 \%$ were not measured at all. Thus, the intercomparison with the FT-ESDR product (Sect. 2.2) was only made when FT-AP data were available for a given date. The time span for this analysis runs from August 2011 with the first Aquarius observations to 31 December 2014 with the latest FT-ESDR data available at the time of our analysis.

\subsection{FT-ESDR product}

The first version of the FT-ESDR product (Kim et al., 2011) was based on an STA similar to the FFrel but applied exclusively to the $\mathrm{TB}_{\mathrm{V}}$ at $37 \mathrm{GHz}$ instead of the NPR. In the new extended product (Kim et al., 2017b; NSIDC: https://nsidc. org/data/nsidc-0477/versions/4), a modified seasonal threshold algorithm (MSTA) was used to determine thresholds for each grid cell to obtain better accuracy. It consists of a gridcell-wise weighted empirical linear regression relationship between the $37 \mathrm{GHz} \mathrm{TB}_{\mathrm{V}}$ measurements and daily surface air temperature (SAT) estimates from the ERA-Interim global reanalysis.

The extended FT-ESDR product used in this study is derived from the SSM/I $37 \mathrm{GHz}$ brightness temperatures (footprint of $38 \mathrm{~km} \times 30 \mathrm{~km}$ ) and resampled at a grid cell resolution of $25 \mathrm{~km}$ on the global Ease-Grid v1.0. The observations were recorded twice per day, which gives the possibility of attributing discrete frozen or thawed states for morning and afternoon. The final classification offers four discrete surface states: "frozen all day", "thawed all day", "frozen in AM and thawed in PM" (transitional) and "thawed in AM and frozen in PM" (inverse-transitional). In this study, the latter two classes were combined into a single transitional class. In order to compare the two products, the FT-ESDR was first spatially resampled to the EASE-Grid 2.0 with the nearest neighbor method choosing the smallest distance between pixel centers. Then, FT-ESDR was temporally resampled for the same weekly calendar as the FT-AP. The temporal FT-ESDR sampling procedure was based on the rule that the most frequently occurring class over the 7 days of a week is adopted as the value for the entire week. In cases where the frozen and thawed classes occurred with equal frequency during a single week (e.g., 2 days frozen, 2 days thawed and 3 days transitional), the transitional class was attributed. This latter class occurs mainly during the transition seasons of spring and fall. Thus, we assigned the transitional class to the thawed class during spring and summer since it indicates the beginning of the thawing process and we assigned the transitional class to the frozen class during fall and winter since it indicates the beginning of the freezing process. This FT-ESDR resampling procedure ensured that the two products were at the same temporal and spatial resolutions with 


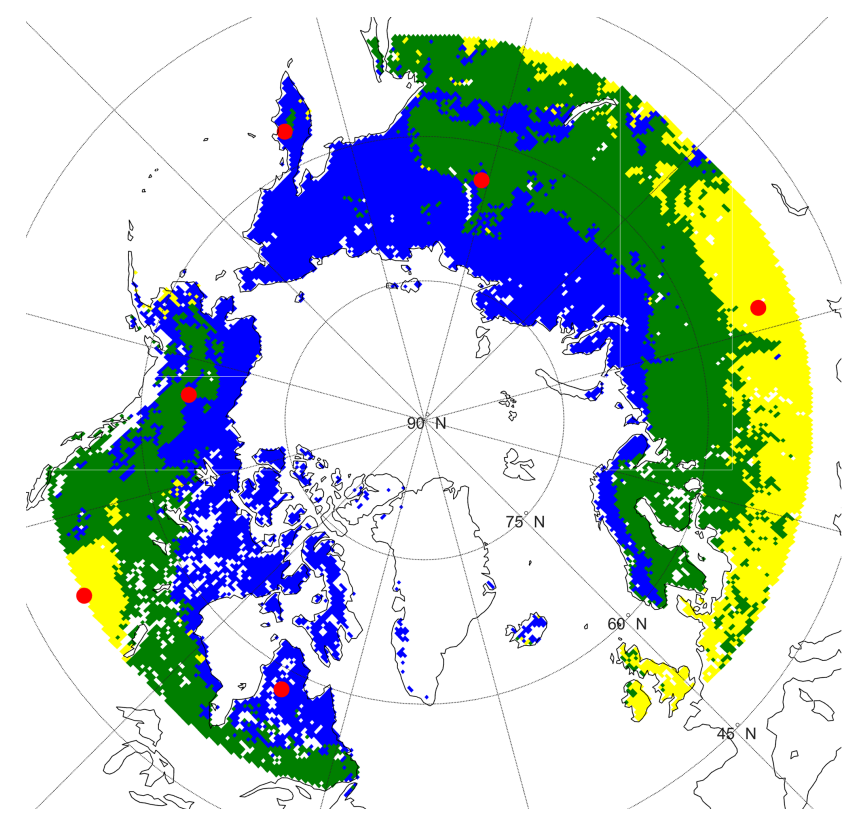

Figure 1. Land cover classes: tundra (blue), forest (green), open land (yellow) and water/ice mask (white). Red dots show weather station locations.

only the frozen and thawed categories, making the comparison possible.

\subsection{Land cover classification}

The land cover information (Fig. 1) comes from the EASEGrid 2.0 LCC $_{\mathrm{BU}}$ (Brodzik and Knowles, 2011; NSIDC: nsidc.org/data/nsidc-0610/versions/1), using the same grid as the FT-AP product. The 17 land cover classes were grouped to obtain four classes: tundra, forest, open land (savanna, cropland and grassland) and water (see Roy et al., 2015). Each grid cell was assigned its single most prominent class of land cover which is used for the selection of its thresholds (Table 1). All grid cells with more than $20 \%$ of water and ice indicated by the $\mathrm{LCC}_{\mathrm{BU}}$ were masked.

\subsection{Weather stations}

Six weather stations (Table 2) were selected for validation from the National Climatic Data Center (NCDC) Climate Data Online website (CDO; https://www.ncdc.noaa. gov/cdo-web/datasets). Two tundra, two forest and two open land sites were chosen for a comparison between the product classifications and the in situ SAT. All of the sites are more than $200 \mathrm{~km}$ from a coast, except the Kamchatka site; its distance of about $85 \mathrm{~km}$ from the sea may have an influence on the large L-band field of view. The average SAT for each day $\left(\mathrm{TAVG}_{\text {day }}\right)$ was used to create a time series for each site. For statistical purposes, the weekly resampling method used on the FT-ESDR product was also applied to the SAT daily val- ues, using $0^{\circ} \mathrm{C}$ as the threshold between frozen and thawed states $\left(\mathrm{TAVG}_{\mathrm{week}}\right.$; see Roy and al., 2015).

Ruggedness values from a 30 arcsec resolution elevation map (Gruber, 2012; University of Zurich: http://www.geo. uzh.ch/microsite/cryodata/pf_global/) were resampled to the EASE-Grid 2.0 with the drop in the bucket approach. In order to represent a ruggedness value at the Aquarius footprint scale, the mean value of a $3 \times 3$ grid cell window centered on each weather station pixel was calculated (Rug_mean). To each value a class was attributed according to the Gruber (2012) classification.

\section{Results}

\subsection{Spatial FT analysis}

Figure $2 \mathrm{a}$ shows the percentage of concordant classifications between the two products for the 3.7-year overlapping period. Overall, the results show that there is good agreement between the two products. In general, forest areas have a better percentage of concordance than other land covers. However, some regions show important discrepancies, especially along coastal margins and in mountainous and open areas (such as in northern Europe, Kazakhstan (and surroundings) and the Canadian Prairies). Those lower percentages correspond to regions where lower accuracies to detect the FT were already noted in Roy et al. (2015) and Kim et al. (2017a) (see Sect. 4). Figure $2 b$ shows that $77.1 \%$ of the common grid cells have more than $80 \%$ agreement. More specifically, $41.6 \%$ of the grid cells have more than $90 \%$ agreement over 3.7 years, with $10.0 \%$ of them having more than $95 \%$. About $35.5 \%$ of the grid cells have an agreement between $80 \%$ and $90 \%$; only $22.8 \%$ of the cells have an agreement lower than $80 \%$.

\subsection{Temporal analysis}

An analysis was made to identify similarities and differences between the two products used for retrieving surface FT state during the freezing (fall) and thawing (spring) periods. For each land cover type, Fig. 3 shows the time series of the fraction of land frozen (for all land at latitudes greater than $50^{\circ} \mathrm{N}$ ). To reduce the effect of obvious false frozen retrievals in summer (discussed below) on the analysis and to focus on the differences primarily related to the physics of the measurements (i.e., L band vs. Ka band), only grid cells with an agreement percentage between FT-AP and FT-ESDR higher than $80 \%$ (from Fig. 2a) were considered. Light blue zones indicate periods for which the FT-ESDR transitional class is set to the frozen class (see Sect. 2.2).

Figure 3 gives information on temporal differences between the products. The difference between FT-AP and FTESDR in terms of the percentage of frozen grid cells for a given day ( $\Delta \%$ frozen) is greatest during the falls in tundra, at $10 \%-27 \%$. In forest, $\Delta \%$ frozen is much lower than 
Table 2. Latitude, longitude and land cover of each weather station. (See also Fig. 1.)

\begin{tabular}{llrrll}
\hline Country/region & Land cover & Lat. & Long. & Ruggedness & Rug_mean \\
\hline Kamchatka/Kljuchi & Tundra & 56.3167 & 160.8331 & undulating & hilly \\
Canada/Quebec & Tundra & 57.9167 & -72.9833 & undulating & undulating \\
USA/Alaska & Forest & 64.7761 & -141.162 & mountainous & mountainous \\
Russia/Siberia & Forest & 63.7831 & 121.6166 & flat & flat \\
Kazakhstan & Open land & 53.2166 & 63.6166 & flat & flat \\
Canada/Saskatchewan & Open land & 50.2666 & -107.733 & undulating & undulating \\
\hline
\end{tabular}
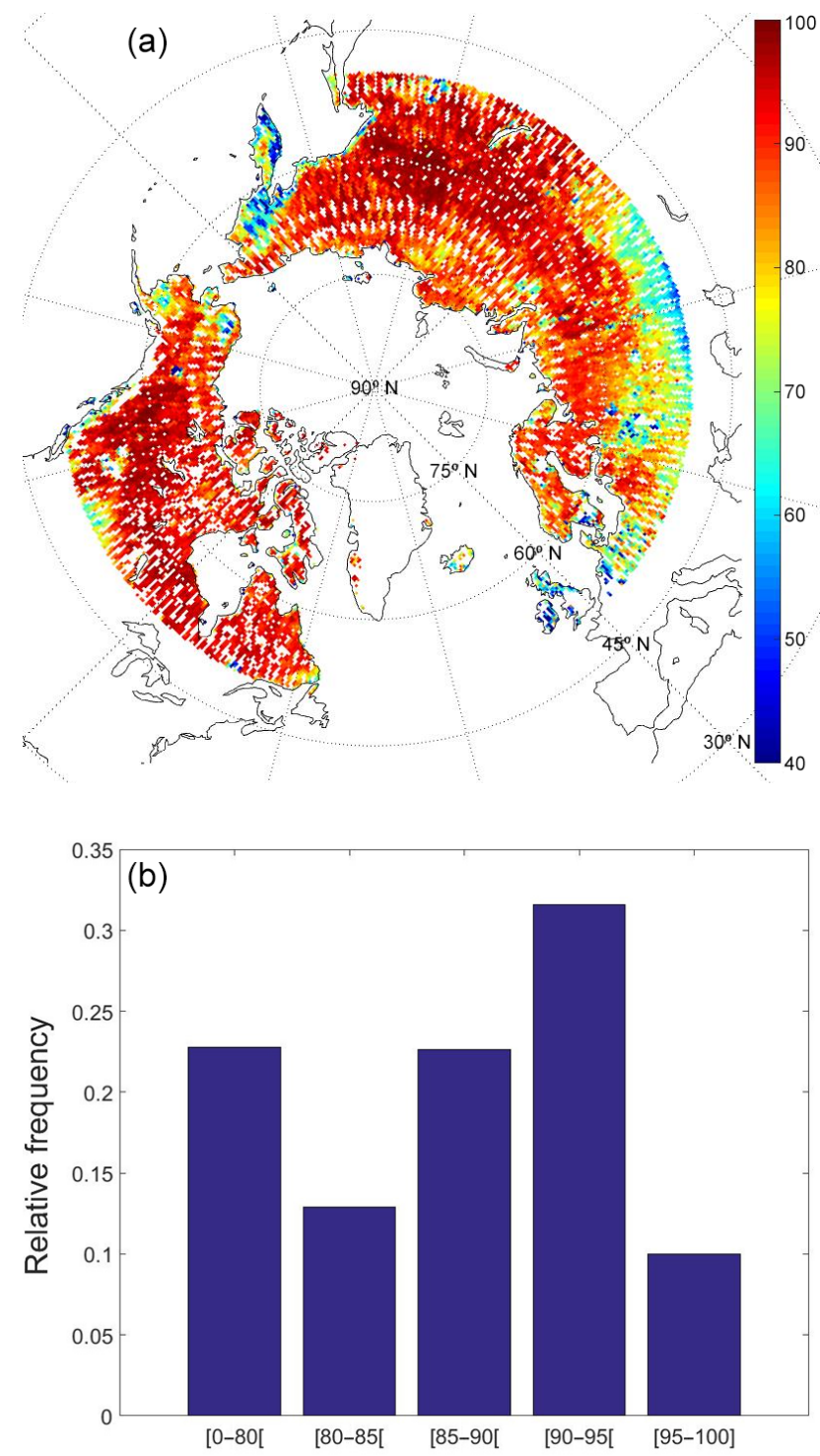

Figure 2. (a) Map of the percentage agreement between FT-AP and FT-ESDR classification for the whole period studied and (b) derived frequency distribution of the mean percentage agreement over the whole study area (lat. $\left.>50^{\circ} \mathrm{N}\right)$. in tundra, with differences of 0\%-12\%. For these two land covers (tundra and forest), the agreement between the products varies by year. In fall, the horizontal shift between the curves indicates time delays ( $\Delta$ time) for the two products to reach the same percentage of frozen grid cells. In tundra, $\Delta$ time ranges from 1 to 3 weeks. In forest, $\Delta$ time is always less than 1 week. This result demonstrates an excellent overall consistency between the products. However, FT-AP shows the percentage of frozen land increasing every summer to a peak that is not perceived with FT-ESDR. In tundra, those maximum values vary between $17 \%$ (2014) and $28 \%$ (2013) and are lower in forest at $7 \%$ (2013) and $10 \%$ (2012). Even if some of those detections represent the real state of the surface, the FT-AP peaks may be mainly caused by false frozen detections, which were noticed in the SMAP product (Derksen et al., 2017). False frozen detections are identified in our analysis using observations from the weather stations (Fig. 6, Sect. 3.3). In open land, FT-AP retrievals tend to vary frequently by showing noticeable unexpected frozen retrievals in summer and thawed retrievals in winter (blue lines in Fig. 3). FT-ESDR shows almost no frozen regions in summer, but unfrozen regions in winter, evidence that the open land regions are at the southern limits of the freeze regions. This in turn makes retrieval more difficult due to the higher temporal variability in FT events in winter.

To spatially represent the information provided by $\Delta$ time, maps in Fig. 4 indicate the week of the year of the freeze onset for each product (top and middle maps). The freeze onset is defined as the first week of the year when the state changed from thawed to frozen and stayed frozen for two more consecutive weeks. This variable can only be identified for grid cells that contain observations over several weeks in a row and have good agreement ( $>80 \%$ ) according to Fig. 2a. Figure 4 also shows the difference in freeze onset between the two products (bottom maps), defined as FT-AP minus FTESDR. A negative value means that FT-AP detects the freeze onset earlier than FT-ESDR (represented by cold colors) and inversely for a positive value (represented by warm colors).

Comparing FT-AP and FT-ESDR maps shows a global tendency of FT-AP to reach the freeze onset 2-5 weeks earlier than FT-ESDR in the tundra regions (blue zones in Fig. 4). In 2013 and 2014 (Fig. 4c, d), this tendency is stronger, with more regions experiencing an earlier freeze 

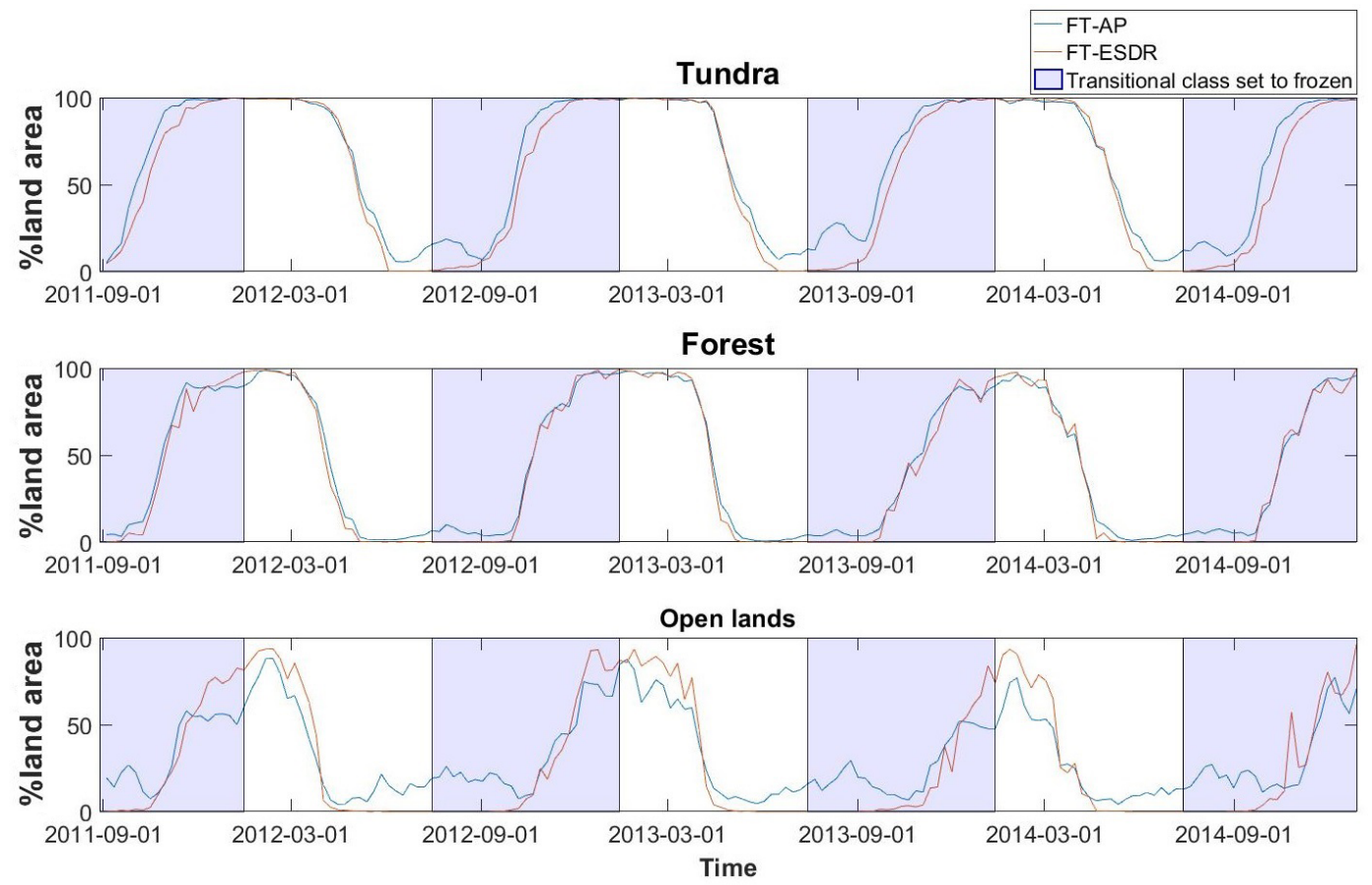

Figure 3. Time series of percentage of frozen grid cells for FT-AP and FT-ESDR for the three land covers (tundra, forest and open lands).
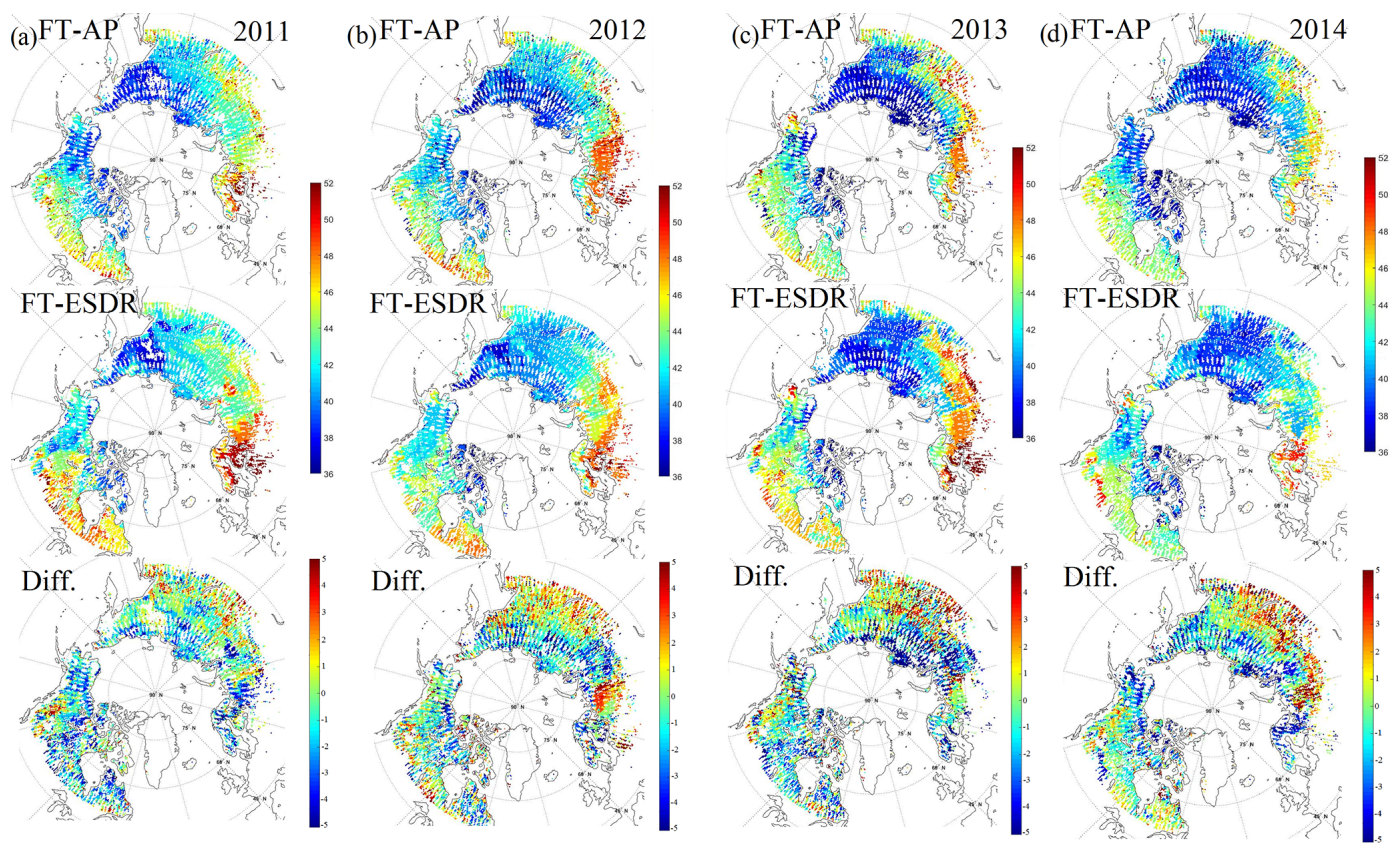

Figure 4. Freeze onset maps, where colors indicate the week of year, for (a) 2011, (b) 2012, (c) 2013 and (d) 2014 with FT-AP (top), FT-ESDR (middle) and difference between the products (Diff. = FT-AP minus FT-ESDR; bottom).

onset by 3-5 weeks according to FT-AP. While these differences are less noticeable in the forest, some local discrepancies are observable with noticeable interannual variabilities.

Table 3 gives freeze onset means $(\mu)$ and standard deviations $(\sigma)$ in weeks of the year for each land cover and year.
Over tundra, it shows the greatest freeze onset mean difference $\left(\Delta \mu=\mu_{\mathrm{FT}-\mathrm{AP}}\right.$ minus $\left.\mu_{\mathrm{FT}-\mathrm{ESDR}}\right)$ between the two products in 2013 , with $\Delta \mu=2.4$ weeks, and the smallest difference in 2011 , with $\Delta \mu=1.3$ weeks. Over forest, the differences are much smaller; the greatest occurs in 2011, 
Table 3. Mean $(\mu)$, standard deviation $(\sigma)$ and mean difference $(\Delta \mu)$ between products of freeze onset date (week of the year) for each land cover.

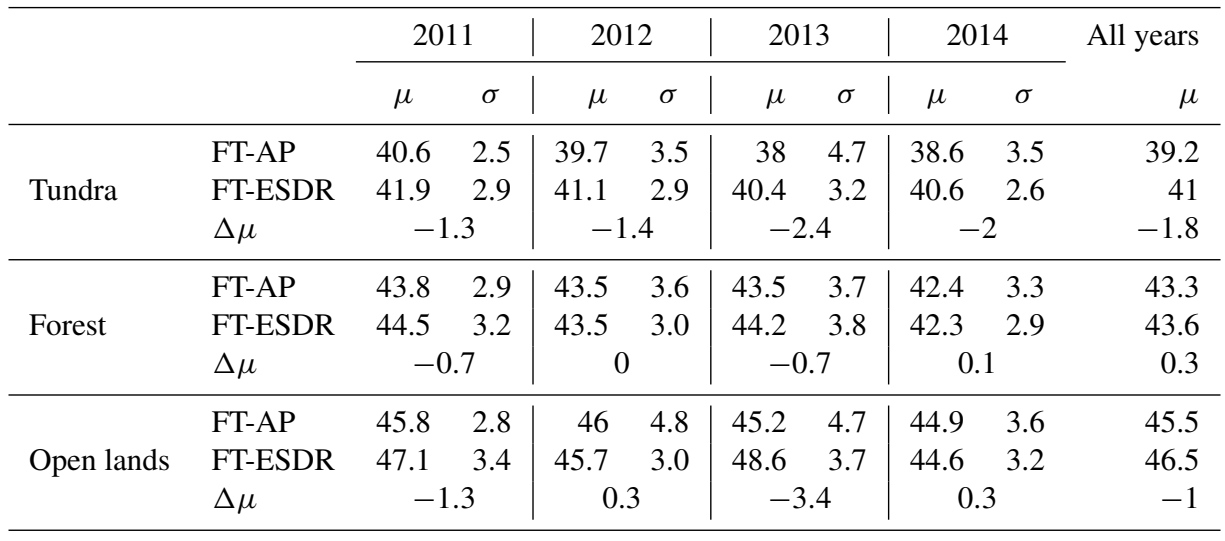

Table 4. Means $(\mu)$, standard deviation $(\sigma)$ and mean difference $(\Delta \mu)$ between products of thaw onset date (week of the year) for each land cover.

\begin{tabular}{|c|c|c|c|c|c|c|c|c|}
\hline & & \multicolumn{2}{|c|}{2011} & \multicolumn{2}{|c|}{2012} & \multicolumn{2}{|c|}{2013} & \multirow{2}{*}{$\begin{array}{r}\text { All years } \\
\mu\end{array}$} \\
\hline & & $\mu$ & $\sigma$ & $\mu$ & $\sigma$ & $\mu$ & $\sigma$ & \\
\hline \multirow{3}{*}{ Tundra } & FT-AP & 19.1 & 3 & 19.1 & 3.2 & 18.8 & 3.6 & 19.0 \\
\hline & FT-ESDR & 18.7 & 2.3 & 18.7 & 2.4 & 18.8 & 2.5 & 18.7 \\
\hline & $\Delta \mu$ & \multicolumn{2}{|c|}{0.4} & \multicolumn{2}{|c|}{0.4} & \multicolumn{2}{|c|}{0} & 0.3 \\
\hline \multirow{3}{*}{ Forest } & FT-AP & 14.7 & 2.3 & 15.4 & 2 & 13.7 & 3 & 14.6 \\
\hline & FT-ESDR & 14.3 & 2 & 15.3 & 1.5 & 14 & 2.4 & 14.5 \\
\hline & $\Delta \mu$ & \multicolumn{2}{|c|}{0.4} & \multicolumn{2}{|c|}{0.1} & \multicolumn{2}{|c|}{-0.3} & 0.1 \\
\hline \multirow{3}{*}{ Open lands } & FT-AP & 11.9 & 2.4 & 13.3 & 3 & 11.2 & 3.5 & 12.1 \\
\hline & FT-ESDR & 12.1 & 1.9 & 14 & 1.7 & 11.6 & 2.9 & 12.6 \\
\hline & $\Delta \mu$ & \multicolumn{2}{|c|}{-0.2} & \multicolumn{2}{|c|}{-0.7} & \multicolumn{2}{|c|}{-0.4} & -0.4 \\
\hline
\end{tabular}

with $\Delta \mu=0.7$ weeks, and the smallest in 2012, with $\Delta \mu=$ 0.0 weeks. As noted for Fig. 4, FT-AP tends to detect freeze onset earlier than FT-ESDR. These freeze onset differences suggest that there is a divergence in the FT signal at L and Ka bands, and that there might be complementary information in the two signals (this is further addressed in the discussion).

For the thawing period, differences between the products according to Fig. 3 and Table 4 are small for all land covers, meaning that globally the two products respond similarly to landscape thaw. This result is consistent across land covers and for the three spring seasons available for this analysis with a stronger variability for open lands. The sensitivity of passive microwave frequencies to the water present in the snow at the beginning of the thaw explains the similarity between the products in spring (Roy et al., 2017a; Hallikainen et al., 1986). Thaw onset maps created from the difference of thaw onset between the products (bottom maps), defined as FT-AP minus FT-ESDR, illustrate the consistency between products, but highlight some local differences (Fig. 5).

\subsection{Comparison with weather stations}

In Sect. 3.1, it was shown that there were some regions where both products show significant discrepancies. In order to better assess the observed variabilities, we looked at six different sites (Fig. 1) to evaluate the temporal evolution of both FT products and compared them to SAT measurements. The objective was to identify any difficulties the products may have monitoring FT in particular conditions. SAT was chosen as the in situ reference since Roy et al. (2015) showed that SAT was the best proxy to validate satellite FT products. Table 5 shows the percentages of agreement of weekly FT detection over the entire period between FT-AP, FT-ESDR and TAVG $_{\text {week }}$ (Fig. 6a-f). The mean agreement between the satellite products and in situ measurement is $81.6 \%$ for FTAP and $92.0 \%$ for FT-ESDR. Discontinuities in the series (Fig. 6a-f) are caused by the absence of Aquarius observations in a given week.

At the Kamchatka site (Fig. 6a, Table 5), FT-AP has a low agreement with $\mathrm{TAVG}_{\text {week }}$ at $67.9 \%$. The error mostly occurs in summers with obvious false frozen misclassifica- 

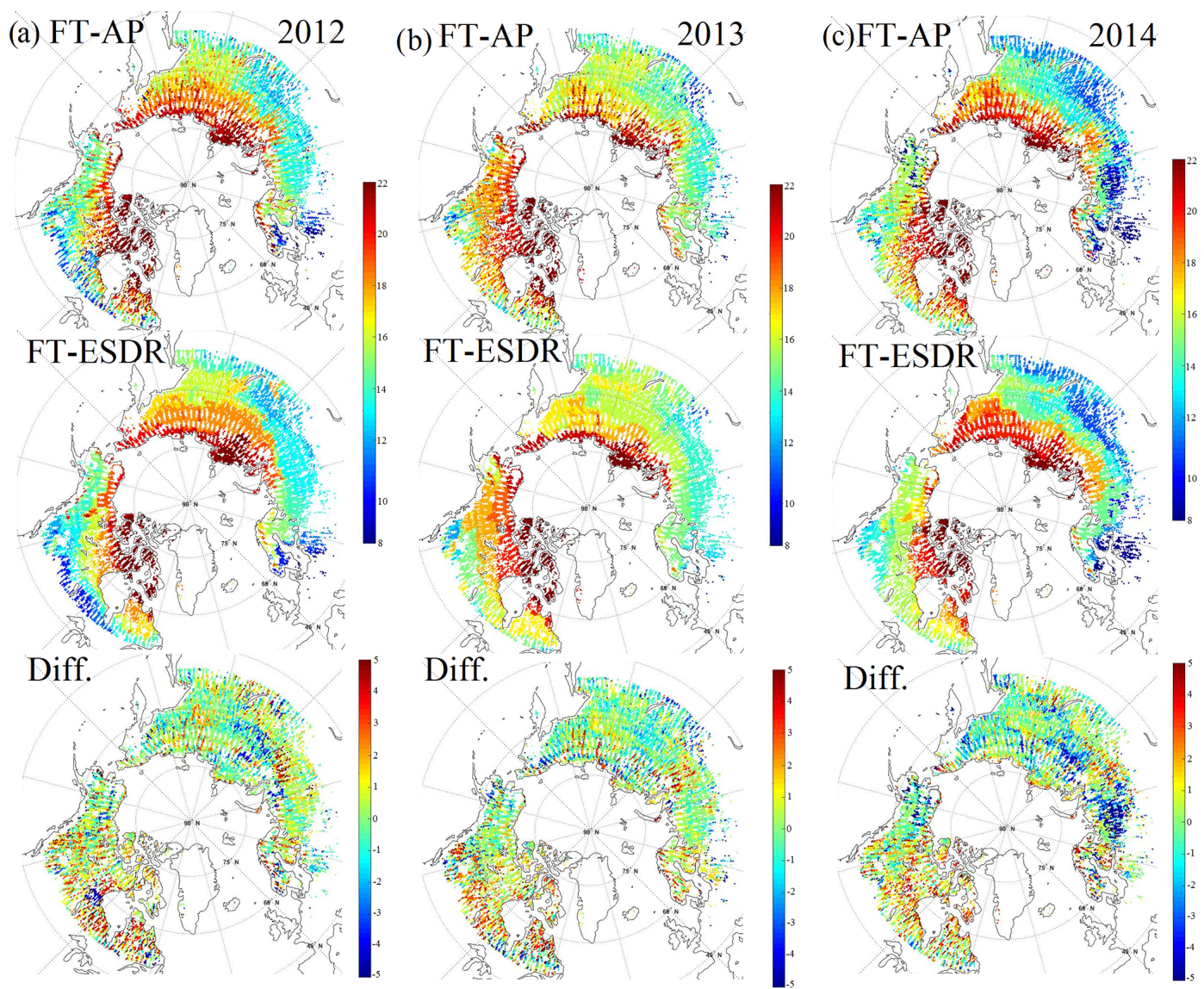

Figure 5. Thaw onset maps, where colors indicate the week of year, for (a) 2012, (b) 2013 and (c) 2013 with FT-AP (top), FT-ESDR (middle) and difference between the products (Diff. = FT-AP minus FT-ESDR; bottom).

Table 5. Agreement (\%) of weekly FT detections between FT-AP and FT-ESDR and between satellite products and in situ data $\left(\mathrm{TAVG}_{\mathrm{week}}\right)$ for each site over the entire period. The sites are defined in Table 2.

\begin{tabular}{llccc}
\hline Country/region & Land cover & $\begin{array}{c}\text { FT-AP-FT-ESDR } \\
(\%)\end{array}$ & $\begin{array}{c}\text { FT-AP-TAVG } \\
(\%)\end{array}$ & $\begin{array}{c}\text { FT-ESDR-TAVG }_{\text {week }} \\
(\%)\end{array}$ \\
\hline Kamchatka/Kljuchi & Tundra & 68.7 & 67.9 & 94.3 \\
Canada/Quebec & Tundra & 83.8 & 90.8 & 89.7 \\
USA/Alaska & Forest & 87.7 & 88.9 & 94.3 \\
Russia/Siberia & Forest & 97.1 & 97.7 & 97.1 \\
Kazakhstan & Open lands & 66.3 & 70.9 & 92.0 \\
Canada/Saskatchewan & Open lands & 76.2 & 73.3 & 84.6 \\
\hline Mean & & 80.0 & 81.6 & 92.0 \\
\hline
\end{tabular}

tions, since SAT is over $0{ }^{\circ} \mathrm{C}$ during that period. In contrast, there is a strong agreement of $94.3 \%$ between FT-ESDR and $\mathrm{TAVG}_{\text {week }}$, with differences occurring in the transitional period with no specific pattern between the years. The difficulty in the retrieval could be due to the fact that the Kamchatka site's grid cell has a very low difference between the minimum and maximum NPR values $\left(\Delta_{\mathrm{NPR}}\right)$ used to create $\mathrm{FF}_{\mathrm{fr}}$ and $\mathrm{FF}_{\text {th }}$, with $\Delta_{\mathrm{NPR}}=0.015$ and $\Delta_{\mathrm{NPR}}=0.021$ for radiometers 2 and 3, respectively. This low difference may lead to a lower sensitivity to FT. Moreover, there is a change of ruggedness classification (Table 2) from the one grid cell ruggedness (SSM/I footprint scale) to the Rug_mean (Aquarius footprint scale) from undulating to mountainous. With a coastline at about $85 \mathrm{~km}$, a major difference of spatial variability exists between SSM/I and Aquarius measurements over the Kamchatka site.

The Quebec site (Fig. 6b), also over tundra land cover, has better product agreements with $\mathrm{TAVG}_{\text {week }}$ than the Kam- 

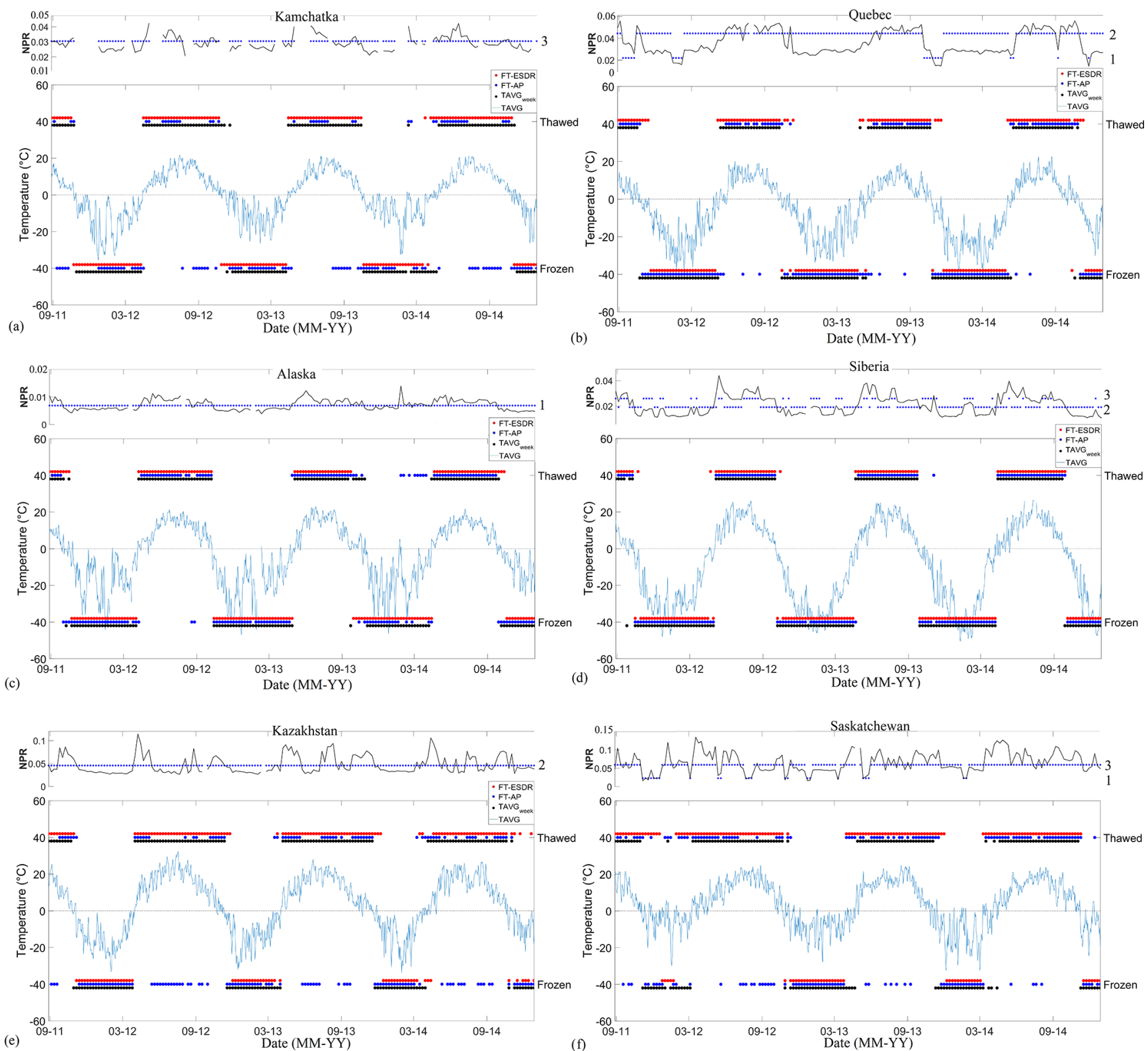

Figure 6. FT detection for each reference site (see Table 2), with FT-ESDR (red dots) and FT-AP (blue dots) against surface air temperature (black dots and blue line) in (a) Kamchatka, (b) Quebec, (c) Alaska, (d) Siberia, (e) Kazakhstan and (f) Saskatchewan. NPR series (top of each panel) contain the combination of available Aquarius observations following the prioritization of radiometer 2, radiometer 1 and then radiometer 3 (Sect. 2.1). NPR threshold values (blue dots) are shown according to Eq. (1), with the corresponding beam number shown on the right.

chatka site, with percentages around $90 \%$. FT-AP generally has a better agreement with $\mathrm{TAVG}_{\mathrm{week}}$ during the fall freezing periods. There are only minor exceptions due to a few false frozen retrievals in summer. These exceptions show a typical situation in which FT-AP detects the freeze onset earlier than FT-ESDR, as mentioned in Sect. 3.2. The relatively high $\Delta_{\mathrm{NPR}}\left(\Delta_{\mathrm{NPR}}=0.024\right.$ and 0.032 for radiometers 1 and 2 , respectively) could be a factor generating fewer false flag retrievals than in the Kamchatka site grid cell.
For forest sites (Fig. 6c-d), both products have good agreement with TAVG $\mathrm{w}_{\mathrm{week}}$. The statistics for the Siberia site highlight the highest agreement: $97.7 \%$ for FT-AP and $97.1 \%$ for FT-ESDR. Interestingly, the forest sites have $\Delta_{\text {NPR }}$ values comparable to those of the tundra sites, with $\Delta_{\mathrm{NPR}}=0.022$ and 0.029 for radiometers 2 and 3, respectively, in Siberia, and a unique $\Delta_{\mathrm{NPR}}=0.010$ for radiometer 1 in Alaska. The latter value is the lowest of all the sites in this study. Since Alaska has relatively good FT-AP agreements $(87.7 \%$ with 
TAVG $_{\text {week }}$ and $88.9 \%$ with FT-ESDR), clearly small differences between $\mathrm{FF}_{\mathrm{fr}}$ and $\mathrm{FF}_{\text {th }}$ alone cannot explain the false frozen retrieval problem at the $\mathrm{L}$ band.

At the open land sites, the low agreement (Fig. 6e-f) between FT-AP and TAVG $_{\text {week }}(70.9 \%$ in Kazakhstan and $73.3 \%$ in Saskatchewan) is mainly due to the false frozen retrieval in summer. During the transitional period, the FT-AP is in good agreement with $\mathrm{TAVG}_{\mathrm{week}}$, sometimes better than FT-ESDR, especially in the fall of 2012, 2013 and 2014 in Kazakhstan. Nevertheless, FT-ESDR agrees relatively well, with $92.0 \%$ in Kazakhstan and $84.6 \%$ in Saskatchewan. The winter of 2011 in Saskatchewan was particularly warm, and the products reacted differently to a succession of events over $0^{\circ} \mathrm{C}$, which affected the overall agreement percentage. The $\Delta_{\text {NPR }}$ values of the open land sites are 0.088 for radiometer 2 in Kazakhstan and 0.029 and 0.095 for radiometers 1 and 3 in Saskatchewan. Consequently, since these are the highest values of all sites, in this case, the false frozen retrievals cannot be explained by a small value of $\Delta_{\mathrm{NPR}}$.

Comparing both products to SAT at different sites shows that FT-AP tends to identify false frozen retrieval in summer periods. It is beyond the scope of this paper to explain why these misclassifications occur, but some hypotheses will be given in Sect. 4.

\section{Discussion}

This study shows that overall FT-AP agrees well with weekly averaged SAT and with the Ka-band FT-ESDR. Despite its being a weekly product, FT-AP has good sensitivity to the FT state of the landscape. Despite some regional discrepancies in forested landscape, very good agreements between FT-AP and FT-ESDR were found in this land cover, suggesting that the sensitivity of L and Ka bands to FT is more similar in forested landscape.

However, the study reveals that in certain regions, FT-AP seems to give false identifications of freezing surface in summer. These findings concord with other L-band FT analyses using SMAP and SMOS (Derksen et al., 2017; Rautiainen et al., 2016). Some regions like the coastlines, Kamchatka, Kazakhstan, Scandinavia, northern Europe, Alaska, the Canadian Rockies and the Canadian Prairies show agreement below $80 \%$ between FT-AP and FT-ESDR. An attempt was made to explain the false frozen retrievals occurring in the Kamchatka site and the two open land sites by looking at the $\Delta_{\text {NPR }}$ values, but no direct relationship was observable. Relatively small $\Delta_{\text {NPR }}$ values are found for Kamchatka, but they are similar to those of Siberia, which has agreement higher than $95 \%$ with $\mathrm{TAVG}_{\text {week }}$. The Alaska site has the smallest $\Delta_{\mathrm{NPR}}$ of all the sites but does not possess the false frozen retrieval problem. To the contrary, the open land sites have the highest $\Delta_{\text {NPR }}$ values and both have frozen retrievals during summer. Hence, $\Delta_{\mathrm{NPR}}$ can explain some of the weak classifications, but not all of them.
The false freeze classification in open land regions could be related to the crop growth cycle. The growing vegetation leads to a stronger emission from the vegetation in both horizontal and vertical polarization (Gherboudj et al., 2012), causing a depolarization of the signal that decreases the NPR. This creates a similar effect to the FT signal and could lead to false freeze identifications in summer (Roy et al., 2015; Rautiainen et al., 2016). Another important factor that could influence the precision of L-band FT retrieval is the possibility of low soil moisture before freezing. Since the FT retrieval is based on $\Delta \varepsilon_{\text {ice/water }}$, low soil moisture will lead to a low FT signal. Hence, in dry regions and where there is irrigation only during the growing season like in Kazakhstan and the Canadian Prairies, dry soil could be misclassified as frozen soil as it has low permittivity.

Moreover, the different initial footprints of the analyzed datasets could also explain some differences between them. For example, coastline proximity likely played a role in the Kamchatka results. Even if the products were resampled at the same scale, the surface heterogeneity such as the fraction of water (lakes and water near coastlines) within the initial footprint could generate changes in FT signals. In mountainous regions, it is possible that intra-pixel freeze onset date variability exists, caused by colder temperatures at higher altitudes in contrast to warmer temperatures at lower altitudes. In this case, the frozen detections in some summer periods could concur with real freezing.

Putting aside those areas, the intercomparison shows recurrent patterns in the global annual freezing and thawing periods. A 2-5-week freeze onset delay is observed in tundra regions every year. Since this pattern is not as clearly seen as in forested area, it is unlikely that the differences come from the algorithm (i.e., STA vs. MSTA methods). The causes are likely related to the physical behavior of microwave emissions at different frequencies, such as differences in emission and sensing depth, vegetation effects (as discussed previously) and ice/snow cover. Rowlandson et al. (2018) and Roy et al. (2017b) showed that the L band is sensitive to the freezing of the very surface related to the strong dielectric discontinuity, while the $37 \mathrm{GHz} \mathrm{TB}$ sensitivity is more related to the land surface temperature variation (Kim et al., 2017a). Hence, it is possible that the higher contrast of ice-water permittivity of the L band would make it more sensitive to the water-ice transition over the large landscape of a pixel (Artemov and Volkov, 2014; Roy et al., 2015; Rautiainen et al., 2012, 2014). However, it remains that both FT products have different algorithms that could also lead to discrepancies. The FT-AP product looks at polarization ratio information, and its calibration is based on the land cover type. On the other hand, FT-ESDR is optimized pixel by pixel using single polarization observations at $37 \mathrm{GHz}$, based primarily on the temperature information. Hence, further detailed ground-based measurements of soil state with radiometric emission at both frequencies could help to better differentiate these effects. 
Table 6. Product name, citation and URL for each dataset used in this study.

\begin{tabular}{|c|c|c|}
\hline Product name & Citation & URL \\
\hline Aquarius TB weekly Level-3 L band & Brucker et al. (2015) & https://nsidc.org/data/AQ3_TB/versions/5 \\
\hline EASE-Grid 2.0 & Brodzik et al. (2014) & https://nsidc.org/data/ease/ease_grid2.html \\
\hline FT-ESDR & Kim et al. (2017b) & https://nsidc.org/data/nsidc-0477/versions/4 \\
\hline Land cover $\mathrm{LCC}_{\mathrm{BU}}$ & Brodzik and Knowles (2011) & https://nsidc.org/data/nsidc-0610/versions/1 \\
\hline Weather stations & & https://www.ncdc.noaa.gov/cdo-web/datasets \\
\hline Ruggedness & Gruber (2012) & http://www.geo.uzh.ch/microsite/cryodata/pf_global \\
\hline
\end{tabular}

Soil heterogeneity makes the comparison with a single punctual in situ SAT limited (McColl et al., 2016; Lyu et al., 2018). While SAT is an indirect way to predict FT status of the soil, it was used because it is a more homogenous reference than soil temperature, which influences the emission (by Planck's law) of landscape elements such as soil, snow and vegetation. Moreover, L-band TB is also sensitive to soil moisture (see the review from Wigneron et al., 2017), which could have a strong spatial variability at the local scale. Microwave emissions detected by a satellite radiometer with all the spatial variability of the environment within a pixel cannot be solely validated by SAT, since it does not consider phenomena like thermal inertia and latent heat exchange.

\section{Data availability}

The FT-AP is archived and distributed by the NASA Distributed Active Archive Center of the National Snow and Ice Data Center (NSIDC DAAC). The FT-AP can be accessed through the NSIDC online public data server (https: //nsidc.org/data/aq3_ft/versions/5, Roy et al., 2018). Table 6 summarizes all the datasets used in this study and lists where they are available for download.

\section{Conclusion}

In recent years, more attention has focussed on the use of satellite observations to retrieve surface freeze-thaw state. The new FT product derived from L-band Aquarius passive observations (FT-AP) ensures, with the SMAP mission that is still in operation, an L-band passive FT monitoring continuum with NASA's spaceborne radiometers, for a period beginning in August 2011. In this study, we evaluated the FT-AP and compared it with a product based on $37 \mathrm{GHz}$ measurements (FT-ESDR). This investigation has shown that FTAP was generally good at retrieving the FT state of the surface for the given time of Aquarius mission, as $77.1 \%$ of the common grid cells have more than $80 \%$ agreement with FTESDR. Differences between the FT-AP and FT-ESDR occur during the complex transitional freezing and thawing periods. The comparison with in situ daily surface air temperature (SAT) showed cases of good concordance with FT-AP and station measurements during those periods. It was also shown that false frozen retrievals in summer with FT-AP also lead to discrepancies between both products. The problem can be caused by surface properties such as vegetation and low soil moisture that influence the L-band NPR.

The study showed that differences between FT products can be caused by the response of frequency to the component in a pixel like vegetation, soil, snow and footprint size. Deeper analysis of multi-frequency differences in relation to FT retrieval is needed. Hence, our results pave the way to look at the fusion of multi-frequency algorithms for FT retrievals from passive microwave satellite observations and upcoming missions like the Water Cycle Observation Mission (WCOM; Shi et al., 2016).

Competing interests. The authors declare that they have no conflict of interest.

Acknowledgements. The authors would like to thank the Canadian Space Agency (CSA) and the National Sciences and Engineering Research Council of Canada (NSERC) for their financial support. Ludovic Brucker was supported by NASA Interdisciplinary Research in Earth Science (IDS).

Edited by: David Carlson

Reviewed by: two anonymous referees

\section{References}

Artemov, V. G. and Volkov, A. A.: Water and Ice Dielectric Spectra Scaling at $0{ }^{\circ} \mathrm{C}$, Ferroelectrics, 466, 158-165, https://doi.org/10.1080/00150193.2014.895216, 2014.

Barr, A., Black, T. A., and Mccaughey, H.: Climatic and Phenological Controls of the Carbon and Energy Balances of Three Contrasting Boreal Forest Ecosystems in Western Canada, in: Phenology of Ecosystem Processes, edited by: Noormets, A., Springer, New York, NY, 2009.

Black, T. A., Nesic, Z., Chen, Z., Chen, W. J., Barr, A. G., Arain, M. A., Neumann, H. H., and Yang, P. C.: Increased carbon sequestration by a boreal deciduous forest in years with a warm spring, Geophys. Res. Lett., 279, 1271-1274, 2000.

Brodzik, M. J. and Knowles, K.: EASE-Grid 2.0 Land Cover Classifications Derived from Boston University MODIS/Terra Land Cover Data, Version 1, [Subset used: $36 \mathrm{~km}$, all land 
classes], NASA National Snow and Ice Data Center Distributed Active Archive Center, Boulder, Colorado, USA, https://doi.org/10.5067/XR8523MC24TB, 2011.

Brodzik, M. J., Billingsley, B., Haran, T., Raup, B., and Savoie, M. H.: Correction: Brodzik, M. J., et al. EASE-Grid 2.0: Incremental but Significant Improvements for Earth-Gridded Data Sets, ISPRS International Journal of Geo-Information 2012, 1, 32-45, ISPRS Int. J. Geo-Inf., 3, 1154-1156, https://doi.org/10.3390/ijgi3031154, 2014.

Brucker, L., Dinnat, E. P., and Koenig, L. S.: Weekly gridded Aquarius L-band radiometer/scatterometer observations and salinity retrievals over the polar regions - Part 1: Product description, The Cryosphere, 8, 905-913, https://doi.org/10.5194/tc-8-905-2014, 2014.

Brucker, L., Dinnat, E., and Koenig, L.: Aquarius L3 Weekly Polar-Gridded Brightness Temperature and Sea Surface Salinity, Version 5, [Subset used: Northern Hemisphere (NH), beam 1, 2 and 3], NASA National Snow and Ice Data Center Distributed Active Archive Center, Boulder, Colorado USA, https://doi.org/10.5067/Aquarius/AQ3_TB.005, 2015.

Derksen, C., Xu, X., Scott Dunbar, R., Colliander, A., Kim, Y., Kimball, J. S., Black, T. A., Euskirchen, E., Langlois, A., Loranty, M. M., Marsh, P., Rautiainen, K., Roy, A., Royer, A., and Stephens, J.: Retrieving landscape freeze/thaw state from Soil Moisture Active Passive (SMAP) radar and radiometer measurements, Remote Sens. Environ., 194, 48-62, https://doi.org/10.1016/j.rse.2017.03.007, 2017.

Gherboudj, I., Magagi, R., Goïta, K., Berg, A. A., Toth, B., and Walker, A.: Validation of SMOS Data Over Agricultural and Boreal Forest Areas in Canada, IEEE T. Geosci. Remote, 50, 16231635, 2012.

Gouttevin, I., Menegoz, M., Dominé, F., Krinner, G., Koven, C., Ciais, P., Tarnocai, C., and Boike, J.: How the insulating properties of snow affect soil carbon distribution in the continental pan-Arctic area, J. Geophys. Res., 117, G02020, https://doi.org/10.1029/2011JG001916, 2012.

Gray, D. M., Landine, P. G., and Granger, R. J.: Simulating infiltration into frozen Prairie soils in streamflow models, Can. J. Earth Sci., 22, 464-472, 1984.

Gruber, S.: Derivation and analysis of a high-resolution estimate of global permafrost zonation, The Cryosphere, 6, 221-233, https://doi.org/10.5194/tc-6-221-2012, 2012.

Hallikainen, M. T., Ulaby, F. T., and Mohamed, A.: Dielectric Properties of Snow in the 3 to $37 \mathrm{GHz}$, IEEE T. Antenn. Propag., 34, 1329-1340, https://doi.org/10.1109/TAP.1986.1143757, 1986.

IPCC: Climate Change 2014: Synthesis Report, Contribution of Working Groups I, II and III to the Fifth Assessment Report of the Intergovernmental Panel on Climate Change, edited by: Core Writing Team, Pachauri, R. K., and Meyer, L. A., IPCC, Geneva, Switzerland, 151 pp, 2014.

Kim, Y., Kimball, J. S., McDonald, K. C., and Glassy, J.: Developing a global data record of daily landscape freeze/thaw status using satellite passive microwave remote sensing, IEEE T. Geosci. Remote, 49, 949-960, https://doi.org/10.1109/TGRS.2010.2070515, 2011.

Kim, Y., Kimball, J. S., Zhang, K., and McDonald, K. C.: Satellite detection of increasing Northern Hemisphere nonfrozen seasons from 1979 to 2008: Implications for regional vegetation growth, Remote Sens. Environ., 121, 472-487, https://doi.org/10.1016/j.rse.2012.02.014, 2012.

Kim, Y., Kimball, J. S., Glassy, J., and Du, J.: An extended global Earth system data record on daily landscape freeze-thaw status determined from satellite passive microwave remote sensing, Earth Syst. Sci. Data, 9, 133-147, https://doi.org/10.5194/essd9-133-2017, 2017a.

Kim, Y., Kimball, J. S., Glassy, J., and McDonald., K. C.: MEaSUREs Global Record of Daily Landscape Freeze/Thaw Status, Version 4 [Subset used: SSMI_37V_CO_FT_xxxx_dayxxx_v04.h5], NASA National, Snow Ice Data Center Distributed Active Archive Center, Boulder, Colorado, https://doi.org/10.5067/MEASURES/CRYOSPHERE/nsidc0477.004, 2017b.

Kumar, N., Grogan, P., Chu, H., Christiansen, C. T., Walker, V. K., and Sciences, M.: The Effect of Freeze-Thaw Conditions on Arctic Soil Bacterial Communities, Biology, 2, 356377,https://doi.org/10.3390/biology2010356, 2013.

Kurganova, I., Teepe, R., and Loftfield, N.: Influence of freezethaw events on carbon dioxide emission from soils at different moisture and land use, Carbon Balance Manag., 9, 1-9, https://doi.org/10.1186/1750-0680-2-2, 2007.

Langer, M., Westermann, S., Heikenfeld, M., Dorn, W., and Boike, J.: Remote Sensing of Environment Satellitebased modeling of permafrost temperatures in a tundra lowland landscape, Remote Sens. Environ., 135, 12-24, https://doi.org/10.1016/j.rse.2013.03.011, 2013.

Lyu, H., McColl, K. A., Li, X., Derksen, C., Berg, A., Black, T. A., Euskirchen, E., Loranty, M., Pulliainen, J., Rautiainen, K., Rowlandson, T., Roy, A., Royer, A., Langlois, A., Stephens, J., Lu, H., and Entekhabi, D.: Validation of the SMAP freeze/thaw product using categorical triple collocation, Remote Sens. Environ., 205, 329-337, https://doi.org/10.1016/j.rse.2017.12.007, 2018.

McColl, K. A., Roy, A., Derksen, C., Konings, A. G., Hamed, S., and Entekhabi, D.: Triple collocation for binary and categorical variables: Application to validating landscape freeze/thaw retrievals, Remote Sens. Environ., 176, 31-42, https://doi.org/10.1016/j.rse.2016.01.010, 2016.

Peng, X., Frauenfeld, O. W., Cao, B., Wang, K., Wang, H., Su, H., Huang, Z., Yue, D., and Zhang, T.: Response of changes in seasonal soil freeze/thaw state to climate change from 1950 to 2010 across china, J. Geophys. Res.-Earth, 121, 1984-2000, https://doi.org/10.1002/2016JF003876, 2016.

Poutou, E., Krinner, G., and Genthon, C.: Role of soil freezing in future boreal climate change, Clim. Dynam., 23, 621-639, https://doi.org/10.1007/s00382-004-0459-0, 2004.

Rautiainen, K., Lemmetyinen, J., Pulliainen, J., Vehvilainen, J., Drusch, M., Kontu, A., Kainulainen, J. and Seppänen, J.: L-band radiometer observations of soil processes in boreal and subarctic environments, IEEE Trans. Geosci. Remote, 50, 1483-1497, https://doi.org/10.1109/TGRS.2011.2167755, 2012.

Rautiainen, K., Lemmetyinen, J., Schwank, M., Kontu, A., Ménard, C. B., Mätzler, C., Drusch, M., Wiesmann, A., Ikonen, J., and Pulliainen, J.: Detection of soil freezing from L-band passive microwave observations, Remote Sens. Environ., 147, 206-218, https://doi.org/10.1016/j.rse.2014.03.007, 2014.

Rautiainen, K., Parkkinen, T., Lemmetyinen, J., Schwank, M., Wiesmann, A., Ikonen, J., Derksen, C., Davydov, S., Davy- 
dova, A., Boike, J., Langer, M., Drusch, M., and Pulliainen, J.: SMOS prototype algorithm for detecting autumn soil freezing, Remote Sens. Environ., 180, 346-360, https://doi.org/10.1016/j.rse.2016.01.012, 2016.

Rowlandson, T., A. Berg, A., Roy, A., Kim, E., Pardo Lara, R., Powers, J., Lewis, K., Houser, P., McDonald, K., Toose, P., Wu, A., De Marco, E., Derksen, C., Entin, J., Colliander, A. and Xu Xiaolan: Capturing Agricultural Soil Freeze/Thaw State through Remote Sensing and Ground Observations: A Soil Freeze/Thaw Validation Campaign, Remote Sens. Environ., 211, 59-70, https://doi.org/10.1016/j.rse.2018.04.003, 2018.

Roy, A., Royer, A., Derksen, C., Brucker, L., Langlois, A., Mialon, A., and Kerr, Y. H.: Evaluation of Spaceborne LBand Radiometer Measurements for Terrestrial Freeze/Thaw Retrievals in Canada, IEEE J. Sel. Top. Appl., 8, 4442-4459, https://doi.org/10.1109/JSTARS.2015.2476358, 2015.

Roy, A., Id, P. T., Derksen, C., Rowlandson, T., Berg, A., Lemmetyinen, J., Royer, A., Tetlock, E., Helgason, W., and Sonnentag, O.: Spatial Variability of L-Band Brightness Temperature during Freeze/Thaw Events over a Prairie Environment, Remote Sens., 9, 1-16, https://doi.org/10.3390/rs9090894, 2017a.

Roy, A., Brucker, L., Prince, M., Royer, A., and Derksen, C.: Aquarius L3 Weekly Polar-Gridded Landscape Freeze/Thaw Data, Version 5, NSIDC: National Snow and Ice Data Center, Boulder, Colorado USA, https://doi.org/10.5067/OV4R18NL3BQR, 2018.

Roy, A., Toose, P., Williamson, M., Rowlandson, T., Derksen, C., Royer, A., Berg, A. A., Lemmetyinen, J., and Arnold, L.: Response of L-Band brightness temperatures to freeze/thaw and snow dynamics in a prairie environment from ground-based radiometer measurements, Remote Sens. Environ., 191, 67-80, $2017 b$.

Schaefer, K., Zhang, T., Bruhwiler, L., and Barrett, A. P.: Amount and timing of permafrost carbon release in response to climate warming, Tellus B, 63, 165-180, https://doi.org/10.1111/j.16000889.2011.00527.x, 2011.

Schwank, M., Stähli, M., Wydler, H., Leuenberger, J., Mätzler, C., Member, S., and Flühler, H.: Microwave L-Band Emission of Freezing Soil, IEEE T. Geosci. Remote, 42, 1252-1261, 2004.
Panneer Selvam, B., Laudon, H., Guillemette, F., and Berggren, M.: Influence of soil frost on the character and degradability of dissolved organic carbon in boreal forest soils, J. Geophys. Res.Biogeo., 121, 829-840, https://doi.org/10.1002/2015JG003228, 2016.

Ulaby, F. T., Moore, R. K., and Fung, A. K.: Microwave remote sensing: active and passive, Volume III: From Theory to Applications, Remote Sen., Artech House, Inc., 1986.

Shi, J., Dong, X., Zhao, T., Du, Y., Liu, H., Wang, Z., Zhu, D., Xiong, C., Jiang, L., Shi, J., and Dong, X.: The Water Cycle Observation Mission (WCOM): Overview, in: 2016 IEEE International Geoscience and Remote Sensing Symposium (IGARSS), Beijing, China, 10-15 July 2016, IEEE, 3430-3433, https://doi.org/10.1109/IGARSS.2016.7729886, 2016.

Wigneron, J., Jackson, T. J., Neill, P. O., Lannoy, G. De, Rosnay, P. De, Walker, J. P., Ferrazzoli, P., Mironov, V., Bircher, S., Grant, J. P., Kurum, M., Schwank, M., Munoz-sabater, J., Das, N., Royer, A., Al-yaari, A., Bitar, A. Al, Fernandezmoran, R., Lawrence, H., Mialon, A., Parrens, M., Richaume, P., Delwart, S., and Kerr, Y.: Modelling the passive microwave signature from land surfaces?: A review of recent results and application to the L-band SMOS \& SMAP soil moisture retrieval algorithms, Remote Sens. Environ., 192, 238-262, https://doi.org/10.1016/j.rse.2017.01.024, 2017.

Xu, L., Myneni, R. B., Iii, F. S. C., Callaghan, T. V, Pinzon, J. E., Tucker, C. J., Zhu, Z., Bi, J., Ciais, P., Tømmervik, H., Euskirchen, E. S., Forbes, B. C., Piao, S. L., Anderson, B. T., Ganguly, S., Nemani, R. R., Goetz, S. J., Beck, P. S. A., Bunn, A. G., Cao, C., and Stroeve, J. C.: Temperature and vegetation seasonality diminishment over northern lands, Nat. Clim. Change, 3, 581-586, https://doi.org/10.1038/nclimate1836, 2013.

Zheng, D., Wang, X., van der Velde, R., Zeng, Y., Wen, J., Wang, Z., Schwank, M., Ferrazzoli, P., Member, S., and Su, Z.: L-Band Microwave Emission of Soil Freeze - Thaw Process in the Third Pole Environment, IEEE T. Geosci. Remote, 55, 5324-5338, 2017. 